Farum

Sociológico

\section{Forum Sociológico}

Série II

$27 \mid 2015$

Mobilidade científica \& imigração qualificada

\title{
Promesas del Sur. Los claroscuros de la experiencia del intercambio de conocimiento y movilidad científica entre América Latina y Europa
}

Cecilia Melella

\section{(c) OpenEdition \\ Journals}

Edição electrónica

URL: https://journals.openedition.org/sociologico/1315

DOI: 10.4000/sociologico.1315

ISSN: $2182-7427$

Editora

CICS.NOVA - Centro Interdisciplinar de Ciências Sociais da Universidade Nova de Lisboa

Edição impressa

Data de publição: 21 dezembro 2015

Paginação: 83-85

ISSN: 0872-8380

\section{Refêrencia eletrónica}

Cecilia Melella, «Promesas del Sur. Los claroscuros de la experiencia del intercambio de conocimiento y movilidad científica entre América Latina y Europa», Forum Sociológico [Online], 27 | 2015, posto online no dia 27 maio 2016, consultado o 31 março 2022. URL: http://journals.openedition.org/ sociologico/1315 ; DOI: https://doi.org/10.4000/sociologico.1315 


\title{
PROMESAS DEL SUR. LOS CLAROSCUROS DE LA EXPERIENCIA DEL INTERCAMBIO DE CONOCIMIENTO Y MOVILIDAD CIENTÍFICA ENTRE AMÉRICA LATINA Y EUROPA
}

\author{
Cecilia Melella \\ Instituto Multidisciplinario de Historia y Ciencias Humanas (IMHICIHU)/ Consejo Nacional de Investigaciones Científicas \\ y Técnicas (CONICET) y Universidad de Buenos Aires
}

Todo discurso, y más aún el discurso ligado al saber cómo el científico o académico, no puede ser leído fuera de las relaciones de poder. Las Ciencias Sociales y Humanidades en América Latina, y particularmente en la Argentina contemporánea, conforman un campo científico consolidado que no escapa a las relaciones de dominación estructurales. Bajo dicha trama, la pregunta central radica en la posibilidad de desarrollar conocimiento autónomo en una región que tradicionalmente ha trabajado bajo el predominio de la luz (y/o la sombra) de la estructura científica hegemónica representada por los países europeos y de América del norte.

A partir de mi experiencia como becaria posdoctoral del Consejo Nacional de Investigaciones Científicas y Técnicas (CONICET) y de la posibilidad de vivir en primera persona la experiencia de intercambio de conocimiento y de movilidad científica que me ha brindado el formar parte del "Proyecto GOVDIV Multilevel governance of cultural diversity in a comparative perspective: EU-Latin America" dirigido por la Dra. Beatriz Padilla me propongo, a través de estas notas de campo, reflexionar acerca de los alcances de burocratización del campo científico y de su posible ruptura, de las viabilidades y contratiempos para la construcción de redes científicas transnacionales, así como de la necesidad y posibilidad concreta de construir un marco intercultural que propicie la comunicación e intercambio científico.

\section{Promesas del Sur}

La Argentina ha transitado durante la última década un proceso de inversión de recursos económicos en las áreas de educación, ciencia y tecnología que se ha visto plasmado en el crecimiento de la cifra de investigadores y de becarios doctorales. Tomo como ejemplo las cifras suministradas en la página Web del CONICET (www.conicet.gov.ar) donde se presenta una totalidad de 3694 investigadores para el año 2003 y de 8865 para 2015. Asimismo, la incorporación de 1840 becarios doctorales en 2003 y de
7900 en 2015. Igualmente, durante dicho período, se han fundado nueve universidades nacionales en todo el territorio argentino. En lo que respecta a los investigadores, en especial a los dedicados a las Ciencias Sociales y Humanidades, este panorama produjo cierta continuidad laboral, la posibilidad de consolidar equipos de investigación productores de conocimiento que involucrasen temáticas y problemáticas autóctonas, la vinculación con las universidades, así como la retribución a la sociedad en general a través de actividades de divulgación y de extensión. Sin embargo, este contexto también produjo interrogantes (bienvenidos sean) sobre el futuro del campo científico, de su inserción en la estructura mundial, de los "pro y de los contra" que implica investigar en y desde América Latina. Así, nos preguntamos: ¿Cómo definimos o qué se entiende en nuestro continente por conocimiento, particularmente, en el campo de las Ciencias Sociales y Humanidades? ¿Hasta qué punto nuestras prácticas científicas cotidianas nos permiten sustraernos de las lógicas burocratizadoras y procedimentales con respecto a la misma producción de conocimiento? ¿Cuáles son los riegos, en especial en torno a la continuidad profesional y laboral, a los que estamos sometidos los jóvenes cientistas sociales en el Cono Sur? ¿Qué aportes nos brinda la realización de un trabajo comparativo y conjunto con investigadores e instituciones europeas?

\section{Hacer investigación desde la jaula de hierro}

En torno al primer interrogante, la producción de conocimiento tanto en América Latina como en Europa se encuentra ligada a la burocratización de las instituciones científicas y de la academia, en tanto que su precepto propone una descontextualización de las intervenciones y una mayor dependencia de factores de poder externos como el Estado (con sus luces y sombras), el mercado y los propios campos científicos particulares. No es novedad que las instituciones científicas se definan por normas colectivas, jerarquías de poder y lógicas presupuestarias, así 
como por normas implícitas "cada vez más visibles" como la asistencia a congresos o reuniones científicas, el formar parte de equipos de investigación y de redes, el ejercicio de la función pedagógica y la evidencia de una máxime de productividad que se materialice en la elaboración de artículos académicos. Si bien esta exigencia fomentada por las nuevas condiciones, por lo menos en la Argentina, del campo científico/académico proporcionan un terreno para el intercambio y la construcción conjunta de conocimiento sobre la base de redes, también genera situaciones en las cuales estos buenos deseos quedan subsumidos bajo una lógica policíaca que "no se pregunta sino que interroga al otro connotativamente" (Barthes, 1993). Uno de los mayores ejercicios de esta lógica policíaca tiene que ver con la imposición de una problemática (al investigador) por el espíritu - sociológico - de la época a través del recorte temático que remite al objeto de investigación y a los modos, técnicas e instrumentos para investigarlo bajo una lógica que acerca peligrosamente al campo académico al bloque en el poder.

Este panorama conlleva el riesgo de caer en el pensar acríticamente y enmarcarse en los universos canónico de moda, llegando así a que el investigador pierda toda conexión con el mundo que lo rodea. El peligro recala en que la legitimidad de un campo de investigación se conforme sobre argumentos de un razonamiento circunscriptos a un nombre propio o a un grupo de instituciones académicas hegemónicas donde la jerarquía exhorta a la supresión de todo pensamiento crítico. Como sostiene Martín Jay (2003) el riesgo consiste en que "el poder del argumento anule completamente la fuerza de los nombres legitimadores".

\section{Intercambio de conocimiento y movilidad científica en los abismos de la inestabilidad}

Por otra parte, el intercambio de conocimiento y la movilidad científica nos brinda la atractiva posibilidad de conformar redes inter e intra-continentales de circulación y reciprocidad que vinculen investigadores, experiencias, instituciones en pos de la generación de conocimiento y de espacios de trabajo conjunto. Nuevamente, el riesgo consiste en que el pensar cuantificado se traduzca en la conformación de grupos de labor en equipo que, lejos de ser entendidos bajo un carácter colectivo de la investigación social, se materialicen en la mera división de trabajo al interior del campo académico. Este modus operandi subsume las distintas investigaciones a conceptos generales y a categorías comunes y deja tras de sí las espontaneidades, pues la lógica de la inestabilidad imperante en las estructuras académicas y científicas conlleva inevitablemente la sustitución. A raíz de mi experiencia de intercambio he llegado a la conclusión de que las redes se desmoronan cuando no hay continuidad laboral para los investigadores y estudiantes sujetos a programas, proyectos o becas de especialización. Lamentablemente, esta característica predomina tanto en la coyuntura latinoamericana como europea. Desde el plano personal, esta situación de precariedad implica un ejercicio de violencia que desmoraliza, malhiere e invisibiliza a quienes resultan concebidos como piezas desechables. Desde el plano colectivo, este tipo de ejercicio del poder contribuye a la creación de una estructura científica que niega en la práctica aquello que pregona desde la semántica y cancela, en un movimiento esquizofrénico, la posibilidad de auto reflexión y de pensamiento crítico. De esta forma, las ciencias sociales resultan transformadas en una industria entre otras dentro de la sociedad capitalista moderna y el trabajo conjunto de investigación deviene en una forma de cosificación del hombre (Adorno, 2001). Esta reducción del individuo no sólo produce la homogeneización del saber, sino que cancela la potencialidad de un pensamiento distinto, nuevo y autónomo. En este sentido, la experiencia de intercambio y movilidad me ha permitido vislumbrar las luces que devienen inescrutablemente de la pregunta auto-reflexiva por los valores dentro del campo científico.

\section{Interculturalidad. Escenario ineludible para el intercambio de conocimiento entre América Latina y Europa}

La historia del conocimiento y de la investigación en América Latina, aún en tiempos de globalización y del paradigma "democratizador" de las tecnologías de la información y comunicación (TIC), se encuentra marcada geohistóricamente, geopolíticamente y geoculturalmente por el eurocentrismo como perspectiva de conocimiento hegemónico. Recuerdo en este momento la frase de Catherine Walsh que señalaba que los centros de capital económico son los centros de capital intelectual. En este sentido, uno de los ejes que aborda el proyecto GOVDIV centrado en la relación entre multiculturalismo e interculturalidad - me interroga, en primer lugar, acerca de las diferencias entre estos paradigmas. El multiculturalismo concibe a la sociedad como la coexistencia híbrida de mundos culturalmente diversos - y la presencia del capitalismo como sistema mundial universal - (Sartori, 2001; Jameson y Zizek, 2003). La multiculturalidad, con su tono descriptivo y propuesta de tolerancia (mosaico) entre culturas, encuentra sus fundamentos conceptuales en las bases del Estado liberal a través de la noción de derecho individual y de la supuesta igualdad donde "la tolerancia del otro" resulta central para asegurar que la sociedad funcione sin mayor 
conflicto dentro de una concepción de producción de conocimiento eurocentrista. Así, el olvido de la dimensión relacional y de la atención a la tolerancia como eje de las relaciones (multi)culturales ocultan la permanencia de las desigualdades sociales que privilegian a unos sobre otros. Asimismo, su versión vivificada como la representada por el pluralismo cultural o la pluriculturalidad refleja la convivencia entre culturas, pero desde la óptica céntrica de la cultura dominante (en América Latina, la "cultura blanca") (Walsh, 2005). Es por ello que, en segundo lugar, me interrogo acerca de la posibilidad de asumir y visibilizar el paradigma intercultural como modelo para accionar desde el campo científico latinoamericano, y en particular desde el grupo de investigación argentino al cual pertenezco, y afrontar esa geopolítica del conocimiento. El pensar la interculturalidad en un contexto de intercambio de experiencias de investigación entre América Latina y Europa conlleva a comprender que la centralidad consiste en poner énfasis en la construcción de una relación equitativa en torno de procesos de reciprocidad que permitan conformar espacios de encuentro entre colegas, saberes, sentidos y prácticas diversas. Interculturalizar en tanto estrategia y proceso constante de construcción, como decía Walsh (2005), implica obrar desde las prácticas micro y cotidianas que organizan las fases de la investigación. El proyecto GOVDIV me brindó la posibilidad de trabajar en concreción de un accionar conjunto sobre lo micro que permita fragmentar las lógicas burocratizantes y plasmar redes sociales científicas recíprocas que funcionen bajo un halo de respeto mutuo y de intercambio horizontal entre colegas de distintas latitudes, pues, para las ciencias sociales, el horizonte de sentido consiste en la construcción de un mundo más justo.

\section{Referencias bibliográficas}

ADORNO, T. (2001), Epistemología y ciencias sociales, Valencia, Cátedra.

BARTHES, R. (1993), Lo obvio y lo obtuso. Imágenes, gestos, voces, Buenos Aires, Paidós.

JAMESON, F. y S. ZIZEK (2003), Estudios culturales. Reflexiones sobre el multiculturalismo, Buenos Aires, Paidós.

JAY, M. (2003), Campos de fuerza. Entre la historia intelectual y la crítica cultural, Buenos Aires, Paidós.

SARTORI, G. (2001), La sociedad multiétnica. Pluralismo, multiculturalismo y extranjeros, Madrid, Taurus.

WALSH, C. (2005), "Interculturalidad, conocimientos y decolonialidad", en Signo y pensamiento, 46 pp. 39-50.

Recebido a 05/10/2015. Aceite para publicação a 04/12/2015.

Cecilia Melella (cemelella@gmail.com). Instituto Multidisciplinario de Historia y Ciencias Humanas (IMHICIHU)/ /Consejo Nacional de Investigaciones Científicas y Técnicas (CONICET) y Universidad de Buenos Aires. Manzoni 1976 to piso depto A, 1407 Ciudad Autónoma de Buenos Aires, Argentina. 